\title{
Combination of preoperative pulmonary and nutritional preparation for esophagectomy ${ }^{1}$
}

Taciana Freitas Agrelli', Marisa de Carvalho Borges', Fernanda Maria Rodrigues da Cunha", Élida Mara Carneiro da Silva', Júverson Alves Terra Júnior"I', Eduardo Crema"'I

'PhD, Physiotherapist, Department of Surgery, Universidade Federal do Triângulo Mineiro (UFTM), Uberaba-MG, Brazil. Intellectual and scientific content of the study, manuscript writing, critical revision.

"MSc, Physiotherapist, Department of Surgery, UFTM, Uberaba-MG, Brazil. Intellectual and scientific content of the study, manuscript writing, critical revision.

I'PhD, Full Professor, Department of Surgery, UFTM, Uberaba-MG, Brazil. Scientific content of the study, technical procedures, critical revision.

\section{Abstract}

Purpose: To compare pulmonary and nutritional parameters before and after inspiratory muscle training (IMT) and enteral feeding support in patients with esophageal disease undergoing preoperative outpatient follow-up.

Methods: Thirty patients with a mean age of 55.83 years, 16 men and 14 women, were included. Pulmonary assessment consisted of the measurement of MIP, MEP, and spirometry. Anthropometric measurements and laboratory tests were performed for nutritional assessment. After preoperative evaluation, inspiratory muscle training and enteral nutrition support were started. A $p<0.05$ was considered statistically significant.

Results: After an outpatient follow-up period of 4 weeks, a significant increase in MIP (-62.20 \pm 25.78 to $-81.53 \pm 23.09)$, MEP $(73.4 \pm 31.95$ to $90.33 \pm 28.39)$, and FVC (94.86 \pm 16.77 to $98.56 \pm 17.44)$ was observed. Regarding the anthropometric variables, a significant increase was also observed in BMI (20.18 \pm 5.04 to $20.40 \pm 4.69)$, arm circumference $(23.38 \pm 3.28$ to $25.08 \pm 4.55)$, arm muscle circumference $(21.48 \pm 3.00$ to $22.07 \pm 3.36)$, and triceps skinfold thickness ( $5.62 \pm 2.68$ to $8.33 \pm 6.59)$.

Conclusion: Pulmonary and nutritional preparation can improve respiratory muscle strength, FVC and anthropometric parameters. However, further studies are needed to confirm the effectiveness of this preoperative preparation.

Key words: Muscle Strength. Enteral Nutrition. Preoperative Care. Esophagectomy. 


\section{Introduction}

The most common esophageal diseases are chagasic or idiopathic megaesophagus and esophageal cancer. The main symptom of the two diseases is dysphagia, first to solid foods and progressively to liquids. Thus, patients reduce food intake, which causes malnutrition, weight loss and immunodepression ${ }^{1,2}$.

Inadequate ventilation and nutritional conditions are major risk factors for postoperative complications. The effects of malnutrition on respiratory muscles have important clinical consequences, including muscle weakness, respiratory failure, decreased effort tolerance, difficulty in weaning patients from mechanical ventilation, and postoperative complications $s^{3,4}$. Esophageal resection is the treatment of choice for earlystage esophageal cancer and other benign esophageal conditions, such as functionally advanced megaesophagus (grades III and IV) ${ }^{5,6}$.

The aim of this study was to compare pulmonary and nutritional parameters before and after inspiratory muscle training (IMT) and enteral feeding support in patients with esophageal disease undergoing preoperative outpatient follow-up.

\section{Methods}

The study was approved by the Research Ethics Committee of UFTM (Protocol No. $660)$. Each patient gave free written informed consent to participate.

A descriptive, prospective, quantitative intervention study was conducted on patients seen during the preoperative period at the Gloria Maria Clinic of the University Hospital, Universidade Federal do Triângulo Mineiro. The sample consisted of 30 patients, 16 (53.4\%) men and $14(46.6 \%)$ women, aged 25 to 78 years (mean age 55.83 ).

Inclusion criteria were age over 18 years, a clinical diagnosis of megaesophagus (grade IV) or esophageal cancer, and undergoing outpatient follow-up before laparoscopic subtotal esophagectomy. Patients who had not participated for at least 4 weeks in the preoperative outpatient follow-up and those with disorientation or comprehension difficulties that prevented them from answering simple questions related to the assessment tools of the study were excluded.

Preoperative pulmonary preparation consisted of IMT for 4 weeks, carried out with the aid of an inspiratory resistor called Threshold (Respironics New Jersey, Inc.). The load used for respiratory strengthening was individualized and corresponded to 50\% of the PImax value recorded. The patient underwent outpatient IMT once a week (3 sets of 10 repetitions) under the supervision of a physiotherapist, and was instructed and encouraged to do the exercises at home during the other days of the week. For this purpose, each patient received a Threshold device for use during preoperative care.

For preoperative nutritional care, individual enteral nutrition support consisting of $1.5 \mathrm{~g}$ protein $/ \mathrm{kg}$ of ideal weight was offered per day to obtain the total volume of the enteral diet administered per day, which was divided into six meals (administered every 3 hours). Intermittent administration was preferable because it facilitates active movement and consequent muscle activity between administrations of the enteral diet, permitting better use of the nutrients offered.

A questionnaire was applied to obtain personal data, clinical diagnosis, and history of present or past disease. Respiratory evaluation consisted of the analysis of respiratory muscle strength, peak flow, and spirometry. For assessment of respiratory muscle strength, maximal inspiratory pressure (MIP) and maximal expiratory pressure (MEP) were measured using an analog manovacuometer 
with an operational limit of $\pm 300 \mathrm{cmH}_{2} \mathrm{O}$ (GeRar, São Paulo, Brazil). At least three measurements of each variable were obtained, with oneminute rest between each maneuver. The highest value was registered since it was not obtained in the third maneuver. If it happened, maneuver would be repeated until it was found a value equal to or below with variation less than $10 \%$ among them. The following spirometry parameters were determined for the evaluation of lung function: forced vital capacity (FVC), forced expiratory volume in the first second $\left(\mathrm{FEV}_{1}\right)$, and $\mathrm{FEV}_{1} / \mathrm{FVC}$ ratio.

Preoperative nutritional assessment consisted of anthropometric and laboratory tests. The following anthropometric parameters were obtained: body mass index (BMI), arm circumference $(A C)$, arm muscle circumference (AMC), and triceps skinfold thickness (TSF). In addition, biochemical parameters were used as markers of visceral protein (albumin and transferrin).

The body mass index was calculated as the ratio between current weight and square of height. Arm circumference was determined with a rigid measuring tape at the midpoint between the acromion and olecranon process of the non-dominant arm, with the arms hanging at the sides. Three consecutive measurements were made by the same examiner and the arithmetic mean, expressed in $\mathrm{cm}$, was considered the final result. TSF was obtained with a Lange caliper at the same site as AC, slightly pulling the skinfold of the nondominant arm away from the muscle tissue. The arm of the subject should be relaxed and hanging loosely at the side of the body. Three consecutive measurements were obtained and the arithmetic mean, expressed in $\mathrm{mm}$, was considered the final result. Muscle arm circumference was calculated using the following equation: $A M C(\mathrm{~cm})=A C(\mathrm{~cm})-$ $0.314 \times \operatorname{TSF}(\mathrm{mm})$. The values obtained were correlated with the reference values in the percentile tables of Frisancho7.

For the determination of biochemical parameters, blood samples were collected after a 12-hour fast in the first evaluation baseline and after 4 weeks. Serum total protein, albumin and transferrin levels were measured using an automated method (Roche ${ }^{\circ}$ ).

Statistical analysis was performed using the Excel 2007 for Windows (Microsoft, USA) and GraphPad Prism 5.0 (GraphPad Software, USA) programs. Continuous variables that showed a normal distribution are expressed as the mean \pm standard deviation. Differences were considered statistically significant when $p$ $<0.05$.

\section{- Results}

The comorbidities observed included hypertension, diabetes mellitus and a history of smoking or alcoholism (Table 1). Twenty-five of the 30 patients had a diagnosis of advanced megaesophagus and five had esophageal cancer. The surgeries carried out were subtotal esophagectomy and Heller myotomy.

Table 1 - Comorbidities in the 30 patients with megaesophagus and esophageal cancer.

\begin{tabular}{ll}
\hline Comorbidities & $\mathbf{n}(\%)$ \\
\hline Hypertension & $8(26.9)$ \\
Diabetes mellitus & $1(3.3)$ \\
Smoking & $11(36.6)$ \\
Alcoholism & $5(16.6)$ \\
No comorbidity & $5(16.6)$ \\
Reported as the mean \pm SD & \\
\hline
\end{tabular}

\section{Respiratory variables}

The respiratory muscle strength and pulmonary function variables are shown in Table 2. 
Maximal inspiratory pressure

There was an increase in MIP after IMT in all patients studied, with the increase being significant after 4 weeks compared to baseline $(p<0.0001)$.

\section{Maximal expiratory pressure}

The MEP values also increased after 4 weeks of training compared to baseline $(p<$ 0.0001).

\section{Pulmonary function}

A significant increase in FVC was observed after 4 weeks of IMT compared to baseline ( $p=0.0108)$. However, no significant increase was found in $\mathrm{FEV}_{1}(p=0.124)$ (Table 2).

Table 2 - Mean value and standard deviation of respiratory muscle strength and pulmonary function parameters before and after respiratory muscle training.

\begin{tabular}{llll} 
& Baseline & After 4 weeks & P \\
\hline Respiratory muscle strength & & & \\
MIP $\left(\mathrm{cmH}_{2} \mathrm{O}\right)$ & $-62.20 \pm 25.78$ & $-81.53 \pm 23.09$ & $<0.0001$ \\
$\mathrm{MEP}\left(\mathrm{cmH}_{2} \mathrm{O}\right)$ & $73.40 \pm 31.95$ & $90.33 \pm 28.39$ & $<0.0001$ \\
Pulmonary function & & & \\
FVC $(\%$ predicted) & $94.86 \pm 16.77$ & $98.56 \pm 17.44$ & 0.0108 \\
FEV $_{1}(\%$ predicted $)$ & $89.18 \pm 21.40$ & $92.81 \pm 22.47$ & 0.1294 \\
FEV $_{1} /$ FVC & $95.43 \pm 14.64$ & $94.15 \pm 12.47$ & 0.7414 \\
\hline
\end{tabular}

$\mathrm{MIP}=$ maximal inspiratory pressure; $\mathrm{MEP}=$ maximal expiratory pressure; $\mathrm{FVC}=$ forced vital capacity; $\mathrm{FEV}_{1}=$ forced expiratory volume in the first second; $F E V_{1} / F V C=$ ratio between forced expiratory volume in the first second and forced vital capacity.

\section{Nutritional variables}

\section{Anthropometric data}

The BMI was significantly higher after enteral nutritional preparation for 4 weeks when compared to the values before preparation $(p<0.0001)$. The same was observed for AC, MAC, and TSF ( $p=0.003, p=$ 0.027 and $p=0.006$, respectively).

\section{Laboratory data}

There was an increase in total protein in the fourth week when compared to baseline values, but the difference was not statistically significant $(p=0.830)$. The same was observed for albumin and transferrin $(p=0.247$ and $p=$ 0.434 , respectively) (Table 3 ).

Table 3 - Mean value and standard deviation of the anthropometric and laboratory data.

\begin{tabular}{llcl} 
& Baseline & After 4 weeks & P \\
\hline Anthropometry & & & \\
$\mathrm{BMI}\left(\mathrm{kg} / \mathrm{m}^{2}\right)$ & $20.18 \pm 5.04$ & $20.40 \pm 4.69$ & $<0.0001$ \\
$\mathrm{AC}(\mathrm{cm})$ & $23.38 \pm 3.28$ & $25.08 \pm 4.55$ & 0.003 \\
AMC $(\mathrm{cm})$ & $21.48 \pm 3.00$ & $22.07 \pm 3.36$ & 0.027 \\
TSF $(\mathrm{mm})$ & $5.62 \pm 2.68$ & $8.33 \pm 6.59$ & 0.006 \\
Biochemical Parameters & & \\
Total protein $(\mathrm{g} / \mathrm{dL})$ & $7.52 \pm 0.92$ & $7.62 \pm 0.64$ & 0.830 \\
Albumin $(\mathrm{g} / \mathrm{dL})$ & $4.04 \pm 0.52$ & $4.18 \pm 0.38$ & 0.247 \\
Transferrin $(\mathrm{mg} / \mathrm{dL})$ & $2.58 \pm 0.29$ & $2.67 \pm 0.38$ & 0.434 \\
\hline
\end{tabular}

$\mathrm{BMI}=$ body mass index; $\mathrm{AC}=$ arm circumference; $\mathrm{AMC}=$ arm muscle circumference; $\mathrm{TSF}=$ triceps skinfold. 


\section{- Discussion}

The incidence of megaesophagus continues to be high in Brazil because of its association with Chagas disease. It is estimated that $5 \%$ to $8 \%$ of the patients with Chagas disease will have megaesophagus ${ }^{8}$. Crema et al. ${ }^{9}$ carried out 60 esophagectomy surgeries and all patients had advanced megaesophagus, 88.33\% secondary to Chagas disease and $11.67 \%$ idiopathic cases. Among our patients with megaesophagus, $84 \%$ had positive serology for Chagas disease.

After abdominal surgery, maintenance of respiratory muscle strength is essential to ensure adequate pulmonary ventilation during the postoperative period. Several studies confirm that IMT is effective in increasing respiratory muscle strength ${ }^{10-12}$. In this respect, Morano et al. ${ }^{13}$ also used the Threshold device for IMT. In their randomized study, patients scheduled for surgical resection of lung cancer were divided into a control group submitted to lung expansion exercises and an intervention group undergoing IMT for 4 weeks before surgery. The authors observed a significant increase in MIP, FVC and the six-minute walk test in the group undergoing IMT with the Threshold device. These findings are consistent with those observed in this study in which IMT performed with the Threshold device for 4 weeks resulted in a significant increase of MIP and FVC.

Preoperative IMT has been shown to decrease the incidence of postoperative pneumonia and length of hospital stay in patients undergoing coronary artery bypass graft surgery ${ }^{14}$. The authors used the same load percentage for IMT as employed in the present study. Barros et al. ${ }^{15}$ tested IMT with a load of $40 \%$ of the initial MIP in patients submitted to conventional physiotherapy combined with IMT using the Threshold device during the postoperative period after coronary artery bypass graft surgery. In a recent study,
Gomes Neto et $a .^{16}$ demonstrated preand postoperative IMT to be a beneficial intervention in the treatment of patients undergoing cardiac surgery. Studies also reported a significant increase in MEP after IMT using the Threshold device, which is consistent with the results found in this work ${ }^{14}$.

Regarding the spirometry variables, we observed a significant increase in FVC after 4 weeks of IMT, similar to the result found by Morano et al. ${ }^{13}$. Dettling et al. ${ }^{17}$ reported that preoperative IMT is feasible in patients with esophageal carcinoma, resulting in significant improvement in respiratory muscle function. In that study, resistance improved significantly after IMT in $32 \%$ and $41 \%$ of the patients, respectively ( $p<0.001)$.

The importance of nutritional care for patients undergoing esophagectomy has been widely recognized and cited in several studies $^{18-20}$. The nutritional status of hospitalized patients directly affects their clinical course, with higher rates of hospital-acquired diseases, higher risk of clinical complications and higher mortality rate among malnourished patients, increasing the time of hospitalization and reducing quality of life ${ }^{21}$.

The relationship between nutritional status and an increased length of hospital stay has been documented, with malnutrition playing a key role in surgical patients, especially because of the risk of postoperative complications. Thus, multivariate analysis comprising anthropometric and biochemical parameters is recommended for the assessment of nutritional status ${ }^{22}$.

No consensus exists regarding the anthropometric measure that best reflects the nutritional status of hospitalized patients, but the rates of recent weight loss and a decrease in $A C, T S F$ and $B M I$ have been used routinely to determine nutritional status ${ }^{23}$. AC is widely employed in field studies since, together with TSF, it is an indicator of protein-calorie malnutrition. Monitoring this parameter over 
time can predict the chronicity of a weight loss process $^{24}$. In the present study, the anthropometric measures were increased after 4 weeks of enteral nutrition support.

Albumin is the most abundant circulating protein in plasma and extracellular fluids. This protein is a key determinant of the colloidal-osmotic pressure of plasma and acts as a transport protein. Albumin is a good indicator for nutritional assessment that is used in almost all studies analyzed, as well as in patients submitted to esophagectomy. A decline in albumin is an accurate indicator of nutritional status and low serum concentrations seem to be associated with postoperative complications ${ }^{25}$. In the present study, no significant increase was found in albumin or total protein after 4 weeks of enteral nutrition support.

Transferrin is a beta-globulin that transports iron in plasma. The half-life of this protein is intermediate (approximately 8 days) between albumin and fast-turnover proteins. High levels of this protein are found in iron deficiency, during pregnancy, in the early stage of acute hepatitis, and in the case of acute red blood cell loss. Low transferrin indicates anemia, infections, chronic liver diseases, neoplasms, and iron overload ${ }^{26}$. In the present study, there was no increase in transferrin after 4 weeks of enteral nutrition support.

A preoperative diagnosis of malnutrition should be understood as a risk factor for developing postoperative complications, longer hospital stays, and higher costs. Thus, the assessment of nutritional status should be included in the determination of surgical risk ${ }^{27}$.

Arora and Rochester (1982), studying 16 malnourished patients, showed a reduction of $63 \%$ in vital capacity, of $35 \%$ in MIP, of $59 \%$ in MEP, and of $41 \%$ in respiratory minute volume. Rochester and Esaú found a reduction of $40 \%$ in MIP predicted in 29 patients with a body weight below the ideal. Our 13 patients with low weight exhibited a reduction of $47 \%$ in MIP and of $42 \%$ in $\mathrm{MEP}^{28}$. Taken together, these data show that malnutrition can compromise respiratory mechanisms and contribute to postoperative complications.

According to Abunnaja et $a l^{29}$, in surgical patients with established malnutrition, nutritional support should begin at least 7-10 days before surgery. Compared to parenteral nutrition, enteral nutrition is associated with fewer complications, shorter hospital stays, and a favorable cost-benefit analysis. In addition, many patients may benefit from the latest enteral formulations, such as immunonutrition, as well as from disease-specific formulations. Nutritional support still plays an important role in perioperative care to prevent postoperative complications and contributes to the early recovery of nutritional status ${ }^{30}$.

\section{Conclusion}

The preoperative respiratory and nutritional preparation can be effective in improving respiratory muscle strength, FVC and anthropometric parameters before esophagectomy. However no significant improvement in the biochemical parameters was observed.

\section{References}

1- Kubo N, Ohira $M$, Yamashita $Y$, Sakurai K, Toyokawa T, Tanaka H, Muguruma K, Shibutani M, Yamazoe S, Kimura K, Nagahara H, Amano R, Ohtani H, Yashiro M, Maeda K, Hirakawa K. The impact of combined thoracoscopic and laparoscopic surgery on pulmonary complications after radical esophagectomy in patients with resectable esophageal cancer. Anticancer Res. 2014 May;34(5):2399-404. PMID: 24778050.

2- Ferguson MK, Celauro AD, Prachand V. Prediction of major pulmonary complications after esophagectomy. Ann Thorac Surg. 2011 May;91(5):1494-1500. doi: 10.1016/j.athoracsur.2010.12.036.

3- Ali Abdelhamid Y, Chapman MJ, Deane AM. Peri-operative nutrition. Anaesthesia. 
2016 Jan;71 Suppl 1:9-18. doi: 10.1111/ anae.13310.

4- Morán López JM, Piedra León M, García Unzueta MT, Ortiz Espejo $\mathrm{M}$, Hernández González M, Morán López R, Amado Señaris JA. Perioperative nutritional support. Cir Esp. 2014 Jun-Jul;92(6):379-86. doi: 10.1016/j. ciresp.2013.12.014.

5- Stahl M, Budach W, Meyer HJ, Cervantes A; ESMO Guidelines Working Group. Esophageal cancer: Clinical Practice Guidelines for diagnosis, treatment and follow-up. Ann Oncol. 2010 May;21 Suppl 5:46-9. doi: 10.1093/annonc/mdq163.

6- Molena D, Mungo B, Stem M, Poupore AK, Chen SY, Lidor AO. Does quality of care matter? A study of adherence to national comprehensive cancer network guidelines for patients with locally advanced esophageal cancer. J Gastrointest Surg. 2015 Oct;19(10):1739-47. doi: 10.1007/s11605015-2899-8.

7- Frisancho AR. New norms of upper limb fat and muscle areas for assessment of nutritional status. Am J Clin Nutr. 1981 Nov;34(11):2540-5. PMID: 6975564.

8- Rassi A JR, Marin JA Neto, Rassi A. Chronic Chagas cardiomyopathy: a review of the main pathogenic mechanisms and the efficacy of aetiological treatment following the BENznidazole Evaluation for Interrupting Trypanosomiasis (BENEFIT) trial. Mem Inst Oswaldo Cruz. 2017 Feb 16:0. doi: 10.1590/0074-02760160334.

9- Crema E, Ribeiro LB, Sousa RC, Terra Júnior JA, Silva BF, Silva AA, Silva AV. Laparoscopic transhiatal esophagectomy for the treatment of advanced megaesophagus. An analysis of 60 cases. Rev Col Bras Cir. 2009 Apr;36(2):118-22. PMID: 20076881.

10-Kendall F, Oliveira J, Peleteiro B, Pinho $\mathrm{P}$, Bastos PT. Inspiratory muscle training is effective to reduce postoperative pulmonary complications and length of hospital stay: a systematic review and metaanalysis. Disabil Rehabil. 2017 Jan 17:1-22. doi: 10.1080/09638288.2016.1277396.

11-Agrelli TF, De Carvalho Ramos $M$, Guglielminetti $R$, Silva AA, Crema $E$. Preoperative ambulatory inspiratory muscle training in patients undegoing esophagectomy. A pilot study. Int Surg. 2012 Jul-Sep;97(3):198-202. doi: 10.9738/
CC136.1.

12-Kulkarni SR, Fletcher E, McConnell AK, Poskitt KR, Whyman MR. Pre-operative inspiratory muscle training preserves postoperative inspiratory muscle strength following major abdominal surgery - a randomised pilot study. Ann R Coll Surg Engl. 2010 Nov;92(8):700-7. doi: 10.1308/0 $03588410 \times 12771863936648$.

13-Morano MT, Araújo AS, Nascimento FB, da Silva GF, Mesquita R, Pinto JS, de Moraes Filho MO, Pereira ED. Preoperative pulmonary rehabilitation versus chest physical therapy in patients undergoing lung câncer resection: a pilot randomized controlled trial. Arch Phys Med Rehabil. 2013 Jan;94(1):53-8. doi: 10.1016/j. apmr.2012.08.206.

14-Valkenet K, Trappenburg JCA, Hulzebos EH, van Meeteren NLU, Backx FJG. Effects of a preoperative home-based inspiratory muscle training programme on perceived healthrelated quality of life in patients undergoing coronary artery bypass graft surgery. Physiotherapy. 2017 Sep;103(3):276-82. doi: 10.1016/j.physio.2016.02.007.

15-Barros GF, Santos Cda S, Granado FB, Costa PT, Límaco RP, Gardenghi G. Respiratory muscle training in patients submitted to coronary arterial bypass graft. Rev Bras Cir Cardiovasc. 2010 Oct-Dec;25(4):483-90. PMID: 21340377.

16-Gomes Neto, Martinez BP, Reis HF, Carvalho VO. Pre- and postoperative inspiratory muscle training in patients undergoing cardiac surgery: systematic review and metaanalysis. Clin Rehabil. 2017 Apr;31(4):45464. doi: 10.1177/0269215516648754.

17-Dettling DS, Van Der Schaaf M, Blom RL, Nollet F, Busch OR, Van Berge Henegouwen MI. Feasibility and effectiveness of preoperative inspiratory muscle training in patients undergoing oesophagectomy: a pilot study. Physiother Res Int. 2013 Mar;18(1):16-26. doi: 10.1002/pri.1524.

18-Miyazaki T, Sakai M, Sohda M, Tanaka N, Yokobori T, Motegi Y, Nakajima M, Fukuchi $\mathrm{M}$, Kato $\mathrm{H}$, Kuwano $\mathrm{H}$. Prognostic significance of inflammatory and nutritional parameters in patients with esophageal cancer. Anticancer Res. 2016 Dec;36(12):6557-62. doi: 10.21873/anticanres.11259.

19-Yoshida N, Baba Y, Shigaki H, Harada K, 
Iwatsuki M, Kurashige J, Sakamoto $Y$, Miyamoto $\mathrm{Y}$, Ishimoto $\mathrm{T}$, Kosumi K, Tokunaga $\mathrm{R}$, Imamura $\mathrm{Y}$, Ida $S$, Hiyoshi $\mathrm{Y}$, Watanabe $\mathrm{M}$, Baba H. Preoperative nutritional assessment by Controlling Nutritional Status (CONUT) is useful to estimate postoperative morbidity after esophagectomy for esophageal cancer. World J Surg. 2016 Aug;40(8):1910-7. doi: 10.1007/s00268-016-3549-3.

20-Mantziari $S^{1}$, Hübner $M$, Demartines $N$, Schäfer M. Impact of preoperative risk factors on morbidity after esophagectomy: is there room for improvement? World J Surg. 2014 Nov;38(11):2882-90. doi: 10.1007/s00268-014-2686-9.

21-Garcia RS, Tavares LR, Pastore CA. Nutritional screening in surgical patients of a teaching hospital from Southern Brazil: the impact of nutritional risk in clinical outcomes. Einstein (Sao Paulo). 2013 Apr-Jun;11(2):147-52. PMCID: PMC4872885.

22-Correia MI, Waitzberg DL. The impact of malnutrition on morbidity, mortality, length of hospital stay and costs evaluatedthrough a multivariate model analysis. Clin Nutr. 2003 Jun;22(3):235-9. PMID: 12765661.

23-Krishnamoorthy V, Sunder S, Mahapatra HS, Verma H, Sharma N, Jayaraman R, Sathi $S$, Khanna S, Mohamed A. Evaluation of protein-energy wasting and inflammation on patients undergoing continuous ambulatory peritoneal dialysis and its correlations. Nephrourol Mon. 2015 Nov 29;7(6):e33143. doi: 10.5812 /numonthly.33143.

24-Segall L, Mardare NG, Ungureanu S, Busuioc M, Nistor I, Enache R, Marian S, Covic A. Nutritional status evaluation and survival in haemodialysis patients in one centre from Romania. Nephrol Dial Transplant. 2009 Aug;24(8):2536-40. doi: 10.1093/ndt/ gfp110.

25-Goh SL, De Silva RP, Dhital K, Gett RM. Is low serum albumin associated with postoperative complications in patients undergoing oesophagectomy for oesophageal malignancies? Interact Cardiovasc Thorac Surg. 2015 Jan;20(1):10713. doi: 10.1093/icvts/ivu324.

26-Kobayashi T, Oshima K, Yokobori T, Idetsu A, Hayashi Y, Hinohara RN, Miyazaki T, Kunimoto $\mathrm{F}$, Kato $\mathrm{H}$, Kuwano $\mathrm{H}$. Perioperative nutriture in esophageal cancer patients undergoing esophagectomy. Hepatogastroenterology. 2013 Sep;60(126):1311-6. doi: 10.5754/ hge11257.

27-Filip B, Scarpa M, Cavallin F, Cagol M, Alfieri R, Saadeh L, Ancona E, Castoro C. Postoperative outcome after oesophagectomy for cancer: Nutritional status is the missing ring in the current prognostic scores. Eur J Surg Oncol. 2015 Jun;41(6):787-94. doi: 10.1016/j. ejso.2015.02.014.

28-Arora NS, Rochester DF. Respiratory muscle strength and maximal voluntary ventilation in undernourished patients. Am Rev Respir Dis. 1982 Jul;126(1):5-8. doi: 10.1164/ arrd.1982.126.1.5.

29-Abunnaja S, Cuviello A, Sanchez JA. Enteral and parenteral nutrition in the perioperative period: state of the art. Nutrients. 2013 Feb 21;5(2):608-23. doi: 10.3390/nu5020608.

30-Sakurai Y, Kanaya S, Uyama I. Recent changes in perioperative nutritional support in patients undergoing thoracoscopic esophagectomy. Nihon Geka Gakkai Zasshi. 2010 Jan;111(1):8-12. PMID: 20158114.

\section{Correspondence:}

Eduardo Crema

Rua Marcos Lombardi, 305

38050-170 Uberaba - MG Brasil

Tel.: (55 34)3318-5228

cremauftm@mednet.com.br

Received: Sep 16, 2017

Review: Nov 17, 2017

Accepted: Dec 20, 2017
Conflict of interest: none

Financial sources: FAPEMIG, CNPq, FUNEPU, and UFTM

${ }^{1}$ Research performed at Department of Surgery, University Hospital, Universidade Federal do Triângulo Mineiro (UFTM), Uberaba-MG, Brazil. 